\title{
Authentic Leadership Theory and Practical Applications in Nuclear Medicine
}

\author{
Sara L. Johnson \\ Nuclear Medicine Technology and Computed Tomography Program, Hillsborough Community College, Tampa, Florida
}

CE credit: For CE credit, you can access the test for this article, as well as additional JNMT CE tests, online at https://www.snmmilearningcenter.org. Complete the test online no later than September 2022. Your online test will be scored immediately. You may make 3 attempts to pass the test and must answer $80 \%$ of the questions correctly to receive $1.0 \mathrm{CEH}$ (Continuing Education Hour) credit. SNMMI members will have their CEH credit added to their VOICE transcript automatically; nonmembers will be able to print out a CE certificate upon successfully completing the test. The online test is free to SNMMI members; nonmembers must pay $\$ 15.00$ by credit card when logging onto the website to take the test.

As the field of nuclear medicine continues to evolve, a need for new leaders will emerge and leadership development will become critical. "Authentic leadership" is an emerging leadership style rooted in humanism that can be used in conjunction with other leadership styles. Authentic leadership has positive implications for health-care settings, including improved patient care, job satisfaction, motivation, collaboration, and knowledge sharing. This article reviews the philosophic foundations of authentic leadership theory and key characteristics of an authentic leader in the context of nuclear medicine.

Key Words: authenticity; leadership; management

J Nucl Med Technol 2019; 47:181-188

DOI: 10.2967/jnmt.118.222851

$\mathbf{T}$ here are many different leadership theories and styles of leadership. Leadership training and development sessions often direct participants to a specific leadership style by describing the leadership style, listing the traits of successful leaders, and then suggesting that participants adopt that leadership style and emulate those specific traits. Although it is important for leaders to learn various leadership theories and attend development sessions, the problem with everyone in an organization ascribing to one style or theory, or individuals emulating traits of others, is inauthenticity. Attempting to emulate traits or a leadership style that does not align with one's personality and values leads to the development of a leadership persona rather than a true leader. Employees recognize the persona as fake, resulting in mistrust, disrespect, and ultimately negative workplace behaviors (1). Authenticity in leadership, on the other hand, has a significant impact on positive

Received Nov. 15, 2018; revision accepted Feb. 7, 2019.

For correspondence or reprints contact: Sara L. Johnson, Nuclear Medicine and Computed Tomography Program, Hillsborough Community College, 4001 W. Tampa Bay Blvd., Tampa, FL 33614.

E-mail: sjohnson215@hccfl.edu

Published online Apr. 24, 2019.

COPYRIGHT (c) 2019 by the Society of Nuclear Medicine and Molecular Imaging. workplace indicators, including job performance, collaboration, and staff retention (2). Recent research has demonstrated that the subscribed theory and style are less important than the authenticity of the leader $(1,2)$.

Authenticity is defined as "the quality of being real or true" (3). The concept of personal authenticity originates from the ancient Greek philosopher Socrates, who lectured on the importance of knowing oneself and staying true to that self (4). Authenticity requires self-awareness and the ability to act in accordance with one's true self (5). "Authentic leadership" theory is a complex theory that applies authentic and humanistic principles to leadership theory with the belief that being true to one's own self will yield more positive results. Authentic leadership theory may be used with any other leadership style and has a significant positive impact on the workplace $(1,6)$.

Authentic leadership has been widely researched in areas of nursing and health-care administration, though no research exists regarding authentic leadership specific to nuclear medicine or medical imaging. Nuclear medicine technologists can be found in various positions of leadership from lead technologists and department managers to educators, board members, industry leaders, and even business owners. Because many current leaders in our field are nearing retirement, a new generation of leaders will emerge. In consideration of the challenges nuclear medicine faces with legislation, reimbursement, encroachment on the scope of practice, and the advances in our field, it is imperative that these leaders be able to lead effectively. This exploratory research seeks to describe the background and characteristics of authentic leadership theory as well as potential benefits as it applies to nuclear medicine.

\section{BACKGROUND}

Authentic leadership was first discussed in the literature in the 1960s, though research has greatly increased over the last decade as unethical business practices have become more publicized. Authentic leadership theory has developed and evolved out of growing frustration with modern 
leadership along with the positive psychology movement of humanism (7). Examples of corruption, including corporate bailouts, abuse of power, and fraud, are well documented and publicized in the mainstream media (4). Authenticity, honesty, and integrity appear to be a rarity in leadership. More recently, highly publicized examples of corporate and political corruption have led to higher demand for authenticity in leadership and a desire for a more ethical approach (4). The champion of authentic leadership theory and research is Bill George, a Harvard University professor and successful businessman. According to George, authenticity is the primary factor in effective leadership, regardless of underlying leadership style (1).

\section{Philosophic Underpinnings}

Authentic leadership is rooted in a humanistic philosophy (4). The central focus of humanism lies in a person's own individual experiences (8). Humanism places a greater significance on human qualities such as self-realization and self-worth. Another major feature of humanism is to assist others in personal development and attainment of what humanists refer to as self-actualization (8). Humanists consider self-actualization to be the highest point of human achievement. Self-actualized individuals lives their life's purpose and fulfill their own unique destiny. In other words, a self-actualized person is authentic. Humanists, particularly Maslow, maintain that the potential for self-actualization exists in everyone (8).
Humanists maintain that behavior is motivated mainly by people seeking to fulfill their own unique life's purpose $(8,9)$. The assumption exists that people are predominately good, as they all strive to discover and actualize their own understanding and purpose. Humanists also believe that environment plays a major role in the development of personality, in intelligence, and in the attainment of goals (8). From this perspective, leadership, work relationships, and work culture play a significant role in individuals' ability to reach their fullest potential. Also, from a humanist perspective, an authentic leader recognizes this relationship and strives to support followers (4).

Arguably the greatest humanistic theory influencing authentic leadership theory is Abraham Maslow's hierarchy-of-needs theory (Fig. 1) (10). Maslow's hierarchy of needs lists 5 basic human goals: physiologic needs, safety needs, a need for love and belonging, a need for esteem, and a need for self-actualization (9). The hierarchy proceeds from the most basic human needs to more complex needs. One cannot progress toward self-actualization without meeting the lower needs of the hierarchy (10).

Physiologic Needs. The physiologic needs are at the bottom of the hierarchy and represent the most basic human needs (10). Examples of these needs include food, drink, and air. Our physiologic needs comprise what is needed to stay alive and for our bodies to maintain homeostasis (10). The most obvious way this connects to authentic leadership

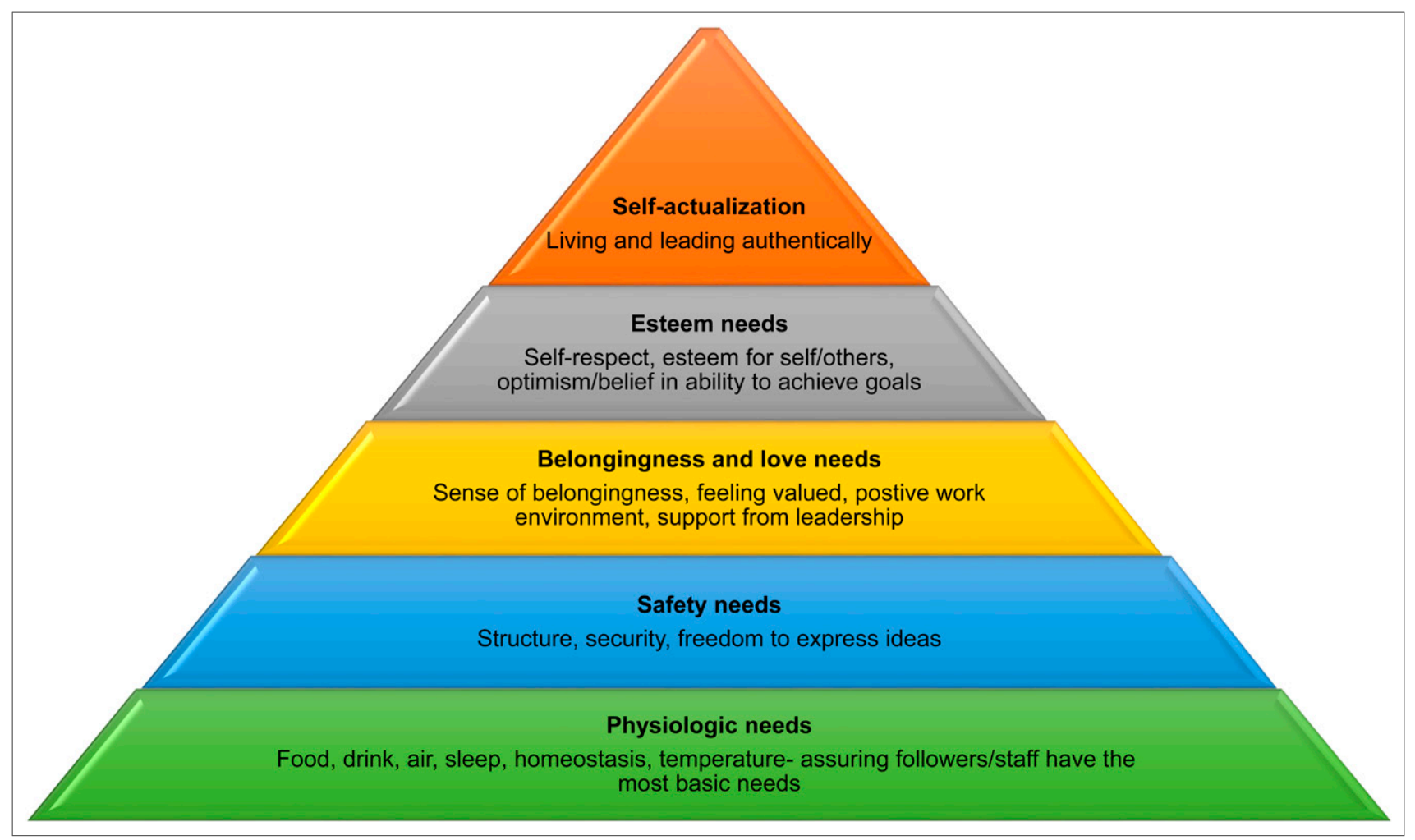

FIGURE 1. Maslow's hierarchy of needs as it applies to authentic leadership. (Adapted from (10).) 
is a leader who ensures that followers have met their most basic needs, such as shelter and food, or ensures that employees have adequate breaks, including time for lunch and bathroom breaks.

Safety Needs. The safety needs represent our need for basic security (10). Before individuals can reach their greatest potential, they need to feel safe and have the freedom to discover their life's purpose, including the freedom to act for that purpose. Examples of safety needs are security, freedom, structure, laws, and stability (9). An authentic leader can help followers meet these needs by working to prevent or correct a hostile workplace, providing structure, clearly defining department rules and protocols, and facilitating an environment in which employees feel free to express ideas and suggest improvements.

Need for Love and Belonging. The need for love and a sense of belonging is basic to humans though more difficult to foster in the workplace. According to Maslow, the need for love and belongingness includes friends, family, affection, and intimacy (10). Although this is a basic human need, it is expressed and received in various ways. The extent to which a sense of belonging is needed may vary greatly from one individual to another. An authentic leader can support followers in meeting this need by encouraging teamwork and a sense of belonging in the workplace. An employee who feels valued is often a more motivated and loyal employee, resulting in a willingness to work harder than an employee who feels undervalued or unwanted (1). An authentic leader who fosters meaningful relationships with followers is supporting fulfillment of this need for belongingness.

Need for Esteem. Maslow describes the need for esteem in terms of having a sense of self-worth, self-esteem, esteem for others, and belief in one's own ability to succeed (10). According to Maslow, as people experience various deficiency needs to various degrees and at various levels, they will develop complex coping behaviors to manage all of them (11). These coping mechanisms must also be managed to achieve self-actualization. People cannot live their life to their fullest potential and perform at their peak without first believing that it is possible (9). Leaders who are striving to lead authentically must develop their own sense of purpose and self-worth and a belief in their own ability to lead effectively. It can be difficult for an authentic leader to develop these same traits in others, though this can be accomplished through modeling, encouragement, and support for personal development.

Need for Self-Actualization. The pinnacle of the hierarchy, self-actualization, represents the ability to live to the fullest potential and the fulfillment of own's own unique life purpose (9). Maslow identified a series of traits displayed in a self-actualized person. These traits include a superior perception of reality, spontaneity, creativity, selfacceptance, autonomy, appreciation for emotional response, deep interpersonal connections, and a democratic character (12). Maslow noted that self-actualized individuals often perform at their peak. Maslow also stressed the importance of personal values and cautioned that adopting the values of others can create an obstacle to self-actualization $(10,12)$. This assertion is crucial to leaders, because the adoption of others' values, traits, or styles that do not align with the leader's personal values creates an obstacle to authenticity and may interfere with the ability to become an effective leader.

Maslow theorized that people are motivated in their development to fulfill a mission, fate, or life's purpose (9). In terms of personal growth, the needs in the hierarchy must be met for the realization of potential and self-actualization to occur. People who are self-actualized act according to their true self to fulfill a life purpose (11). In this regard, one's ability to live and lead authentically is closely tied to humanistic philosophy and what Maslow referred to as self-actualization.

Humanism and Maslow's hierarchy-of-needs theory have greatly influenced human resource and business theory, particularly authentic leadership theory (5). According to Maslow, everyone has the potential to reach self-actualization once their other more basic needs are satisfied $(8,10)$. For leaders to be successful, to lead with purpose, and to perform at their highest potential, they must continuously evaluate their own life in this context. The leader must address the needs of self before successfully leading others. This humanistic approach requires leaders to invest in people and help others reach their highest potential as well (8). Authentic leadership theory requires the leader to focus on engaging with and supporting the follower. A focus on personal relationships and helping others achieve their life's purpose is one aspect that gives authentic leadership a humanistic foundation.

\section{Leadership Theory}

In addition to a humanistic psychologic foundation, authenticity in leadership is a complex theory with similarities to several other leadership theories (6). Authentic leadership theory is most like the relational styles of leadership, such as the servant, transformative, charismatic, spiritual, and ethical styles (6). The servant and transformative styles are the two relational leadership styles that are most closely connected to authenticity (6).

Servant leadership has many similarities to authentic leadership, including a component of morality and the desire for leaders to put the needs and goals of others in the forefront $(6)$. The main tenet of servant leadership is the leader's ability to listen to the followers (13). Servant leaders have an altruistic desire to improve the lives of others, thus placing great emphasis on the human aspect of followers. Servant leaders also strive to help followers develop into a next generation of leaders who will also serve (13). Authentic leadership is similar to servant leadership in the focus on humanistic qualities, altruism, and helping others develop personally and professionally $(6,13)$.

Transformational leadership, however, may be the largest contributor to the authentic leadership theory. Key components 
of a transformational leader include raising the followers' levels of consciousness regarding the value of outcomes and how to obtain them, inspiring followers to put the needs of the organization above self, and altering the need level of Maslow's hierarchy of needs to facilitate self-actualization and the reaching of one's best potential $(4,14)$. Transformational leadership shares with authentic leadership a humanistic approach that attends to the needs and goals of the follower. The first mentions of authentic leadership in the academic literature appeared as a subtype of transformational leadership, claiming that transformational leadership may be either authentic or inauthentic (4).

Relational leadership styles such as servant or transformational leadership do have similarities to authentic leadership, though authentic leadership is unique in that it can be combined with any leadership style (6). The development and research of authentic leadership theory have emerged out of frustration with inauthentic leaders in various leadership styles, though good examples of leaders are found across those same styles, leading to the question of what truly makes a leader successful. Proponents of authentic leadership claim that success in any style of leadership is heavily reliant on leader authenticity (1). Regardless of leadership style, a leader must be true to oneself and authentic in action. George maintains that leadership style is inconsequential because authenticity is a true mark of success in leadership (1). Authentic leadership theory emphasizes that leaders are free to adopt or develop their own leadership style so long as that style is consistent with their own character and values.

\section{AUTHENTIC LEADERSHIP THEORY}

Authentic leadership theory maintains that there are 3 factors that influence the development of an authentic leader: positive psychologic capabilities, moral reasoning, and critical life events (4). Positive psychologic capabilities include balanced cognitive reasoning and resilience. Resiliency and balanced reasoning are the skills that enable a leader to overcome difficulties, face challenges, and see alternative perspectives when making difficult decisions. Leaders with a balanced cognitive processing capability see multiple perspectives and consider all information objectively (15). Balanced processing includes making objective decisions while taking into account all opinions and relevant information. Leaders with this characteristic often solicit views that challenge their own when making decisions (2).

Moral reasoning describes the decision-making process needed to address moral and ethical dilemmas, whereas critical life events refer to hardships or personal crises that enable people to grow (6). Authentic leaders typically have life stories in which a tragedy or series of tragedies helped that leader gain self-awareness and discover the life purpose that supports the authenticity in leadership (16). In their research, Shamir and Eilam discovered that it is through life stories "that people can develop a self-concept of a leader that supports and justifies their leadership role because the life-story not only recounts but also justifies" (16). In other words, critical life events often enable the leader to gain a better sense of compassion and humanism, which helps the leader relate to followers. An underlying positive psychology and moral reasoning combined with critical life events supports the development of key characteristics of authentic leaders.

\section{Characteristics of an Authentic Leader}

Authentic leaders possess distinguishing characteristics (Fig. 2) (5). One prominent characteristic is the belief that humans are the most important asset. This human resource framing helps the leader to lead with purpose, build authentic relationships, and make balanced and objective decisions (5). Authentic leaders know and recognize that they are not perfect; they have a strong understanding of their own personal strengths and weaknesses, as well as a strong desire to work toward a defined purpose (6). Authentic leaders will strive to develop their natural strengths while also working to overcome their own shortcomings. Personal qualities include confidence, resilience, hopefulness, optimism, and a high moral character. Authentic leadership theorists have identified 5 key characteristics of an authentic leader: being capable of moral reasoning, leading with the heart, maintaining relationships, being self-disciplined, and having a defined purpose (1). Without the development of these important characteristics, authenticity cannot exist.

Being Capable of Moral Reasoning. Leaders with strong moral reasoning have a desire to make a difference in the world. Authentic leaders are guided by a mission and hold deeply rooted personal values (5). It is imperative for an authentic leader to have a deep understanding of personal values and to always act in accordance with those values. Leaders are examined carefully by others and defined by

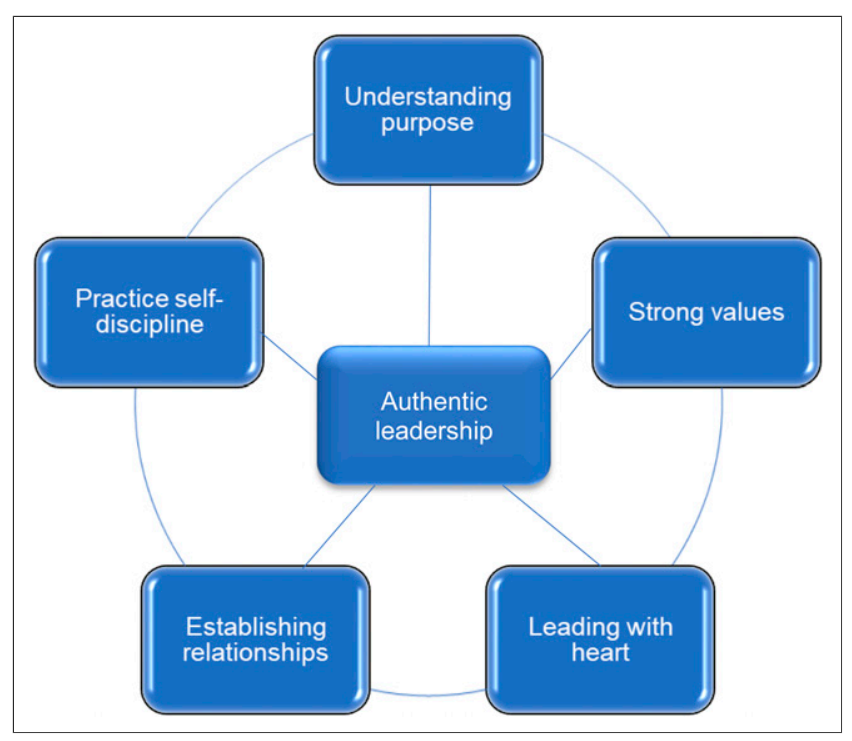

FIGURE 2. Characteristics of an authentic leader. (Adapted from (1).) 
their values and character. An authentic leader has a strong sense of right and wrong and allows those values to guide challenging decisions because it is difficult to trust or follow a leader who lacks integrity (7). Through the introspection of becoming self-aware, authentic leaders should discover their moral compass and possess a strong sense of personal morality and values $(1,4,6)$. A leader must have a strong grasp on personal values when confronting the tough decisions and ethical dilemmas that often come with leadership positions (1).

Leading with the Heart. Authentic leaders often have had personal tragedies in their own lives that enable them to have compassion for others (4). Leading with the heart also requires the leader to be open and honest with employees. This practice helps build a solid relationship with the followers built on trust and mutual respect $(1,4,6)$. It also helps followers to have their own sense of purpose, which in turn makes them more intrinsically motivated (1). A leader who fails to lead with the heart or demonstrate compassion for followers undermines the relationship and trust between leader and followers.

Maintaining Relationships. The ability to establish and maintain relationships is essential to authentic leadership, particularly relationships with followers. George states, "The detached style of leadership will not be successful in the twenty-first century. Today's employees demand more personal relationships with their leaders before they will give themselves fully to their jobs" $(1,2)$. Authentic leaders, on the other hand, view their followers as a team with a collective set of knowledge and skills. Authentic leaders see each follower as an important part of the group. They strive to develop a sense of connectedness and a shared purpose. Taking the time to develop lasting relationships with followers may result in more commitment and loyalty from followers. A recent study by Alilyyani et al. found that building relationships with followers had a significant impact on trust, work engagement, collaboration, and job performance (2). Along with establishing relationships is relational transparency, which is the extent to which a person presents a true self to close colleagues, family, and friends (5). Relational transparency requires a fine balance of open expression without inappropriate displays of emotion (2). Authentic leaders have authentic relationships.

Being Self-Disciplined. It is essential that an authentic leader practice self-discipline (2). Leader behavior is always under a microscope. It is imperative that an authentic leader be able to rise above the pressure and stresses which may cloud judgment or lead to inconsistent behavior $(1,2)$. Inconsistencies may exist between words and actions or in actions between one situation and the next. Followers will not trust a leader who preaches one thing but does another or does not follow the rules set for others. Failure to remain consistent will eventually lead to mistrust and disrespect. The practice of self-discipline extends beyond the workplace. Authentic leaders must also practice self-discipline in all areas of life, because inconsistencies between work and home life will eventually lead to mistrust and disrespect from followers.

Having a Defined Purpose. Self-awareness includes defining and understanding one's purpose as a leader $(1,4,6)$. Authentic leaders must understand their unique purpose and have a passion for fulfilling that purpose (1). For department managers or lead technologists, the primary purpose may be to unify and motivate the staff technologists, implement cost-saving measures, or lead the department through updates and expansion. For educators, the purpose may be to ensure that the next generation of nuclear medicine technologists enters the workforce as knowledgeable and competent individuals who are prepared to work in and advocate for the field. Whatever the purpose may be, the process of discovering that purpose requires introspection and is uniquely the leader's to define. It is also important to have a passion for this purpose. Having a passion for the purpose lends itself to intrinsic motivation $(1,4)$.

\section{BECOMING AN AUTHENTIC LEADER}

Leading with authenticity is not a goal or a final achievement; it is a journey (Fig. 3). The most difficult part of the process for most leaders is self-awareness. The process of understanding oneself requires the courage to be honest and vulnerable enough to embrace the darkest parts of self. It takes years of personal growth, introspection, and hard work. It also takes adopting the humanistic belief that all people are good at their core and are striving to do their best. It is impossible to overcome our obstacles, especially the obstacles we create for ourselves, unless we understand they exist. To lead authentically, one must discover and reflect on one's own strengths and weaknesses.

\section{Self-Awareness}

Self-awareness is the process by which one comes to understand one's own self. It is an ongoing process rather than an achievement. Self-awareness includes an understanding of strengths, weaknesses, values, morals, and perspectives (15). Self-awareness includes not just being aware of weaknesses but also accepting them. This process of identifying and accepting one's own weaknesses can be extremely difficult and may require a great deal of time and personal commitment. Authentic leaders are self-aware in a way that includes a firm understanding of their individual life purpose (16). Self-awareness may be the initial starting point of authentic leadership. Without understanding oneself, one cannot truly lead authentically.

Several tools, such as personality tests, exist for helping leaders become more self-aware or discover and create a personal leadership style. Avolio et al. developed an evidence-based tool, the Authentic Leadership Questionnaire, which was validated in 2008 (6,17). The Authentic Leadership Questionnaire measures the extent of authenticity rather than developing authenticity in a leader. For leaders seeking to lead authentically, this questionnaire may be 


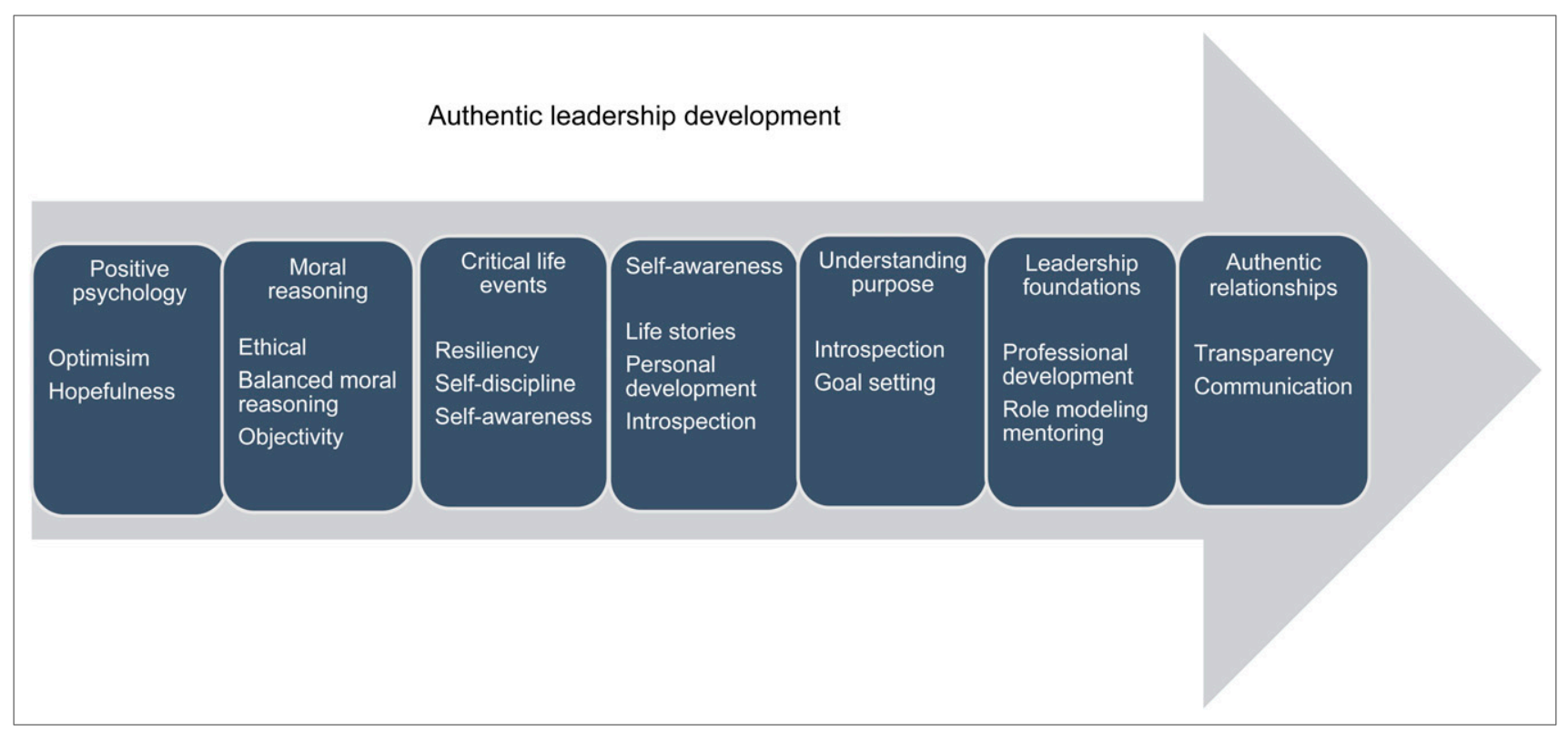

FIGURE 3. Development of an authentic leader.

helpful in revealing areas where improvements are needed. Regardless of the tools used, getting to know oneself and understand one's role as a leader is the first step (18). Once this is better understood, a leader will set goals and create action plans to lead with purpose. Next, the authentic leader will take the time to know the followers and understand their goals. Authentic leadership develops over time through practical application and personal evolution.

\section{The Leader-Follower Relationship}

Leaders do not exist without followers, making forging a relationship with followers an important step in the process of becoming an authentic leader. Authentic leadership theory relies on a bonded natural relationship between the leader and the follower (15). An authentic leader supports the follower in achieving self-actualization. As the leader strives to help the follower achieve this goal, the follower must trust the leader (16). Authentic followers value the personal relationship with the leader but do not have delusions about the leader. Followers understand that the leader is flawed but have respect for the leader and embrace their differences (16). Authentic leadership theory maintains that it is the followers who identify a leader as authentic, underlining the important role of the leader-follower relationship. Followers authenticate the leader and follow authentically (16). The development of the leaderfollower relationship is vital to the leader's development.

\section{IMPLICATIONS FOR THEORY AND PRACTICE}

Many research studies have examined the relationships between authentic leadership and workplace behaviors or attitudes $(4,7,14,15,19)$. Braun and Peus, for example, examined work-life perceptions to reveal a significant relationship between authentic leadership and job satisfaction
(20). As the perceptions of the leader improved and followers identified the leader as authentic, the followers' perceptions of work-life balance, overall work culture, productivity, collaboration, and job satisfaction improved. Furthermore, these work-related improvements exist in both attitudes and behaviors when a leader is identified as authentic (Table 1). When followers feel supported and valued as members of a team and have an authentic and open relationship with leadership, research has noted a perception of improved work-life balance, improved motivation, and decreased stress (20). These improvements ultimately lead to greater efficiency, better quality of work, and more attentive and service-oriented patient care.

Authentic leadership theory is not without shortcomings. The importance of life stories to the development of resiliency and other traits will vary greatly. Each life story will be impacted by outside factors such as race, sex, and socioeconomic level (1). The concepts of authenticity and leadership may also vary according to culture. Further, critics of authentic leadership theory note that authenticity may have social constraints or barriers that prevent cultural, ethnic, and sexual diversity in leaders (1). Additionally, the theory of authentic leadership is reliant on the leader's ability to personally develop self-awareness and facilitate transparent relationships, which may be very difficult to achieve without a great deal of time, commitment, and dedication to personal improvement.

\section{AUTHENTIC LEADERSHIP IN NUCLEAR MEDICINE}

Returning to the humanistic core of authentic leadership theory, an authentic leader seeking to develop and motivate followers to reach their highest potential will ensure that the followers' lower-level, more basic needs are met. According 
TABLE 1

Organizational Benefits of Authentic Leadership

\begin{tabular}{|c|c|}
\hline Category & Benefit \\
\hline \multirow{7}{*}{$\begin{array}{l}\text { Leadership } \\
\text { characteristics }\end{array}$} & Self-awareness \\
\hline & Sense of purpose \\
\hline & Balanced and objective decision making \\
\hline & Desire to make difference in world \\
\hline & Relational transparency \\
\hline & Self-discipline \\
\hline & Strong values/ethical \\
\hline \multirow{6}{*}{$\begin{array}{l}\text { Attitudinal } \\
\text { outcomes }\end{array}$} & Trust in leader \\
\hline & Improved work-life balance perception \\
\hline & Job satisfaction \\
\hline & Organization commitment/loyalty \\
\hline & Reduced stress and burnout \\
\hline & Increased motivation \\
\hline \multirow{6}{*}{$\begin{array}{l}\text { Behavioral } \\
\text { outcomes }\end{array}$} & Increased efficiency \\
\hline & $\begin{array}{l}\text { Knowledge sharing and } \\
\text { collaboration }\end{array}$ \\
\hline & Improved outcomes \\
\hline & Improved patient care \\
\hline & Improved patient satisfaction \\
\hline & $\begin{array}{l}\text { Decreased patient accidents } \\
\text { and medical errors }\end{array}$ \\
\hline
\end{tabular}

to authentic leadership theory, employees who do not feel a sense of belonging are less likely to have confidence and esteem in their work and therefore will be unable to perform to the highest potential (6). Lead technologists, educators, and department managers seeking authenticity should be cognizant of the needs of the followers and make efforts to ensure that those needs are met. This may be as simple as communicating to determine where deficiencies exist, supporting followers with positive feedback in addition to feedback on areas of needed improvement, and ensuring that technologists who are on call have had adequate rest.

General leadership skills are a critical necessity in the health-care context, as suggested by health-care leadership experts, though authenticity has additional benefits. Specifically, research has shown authentic leadership to have many benefits in a health-care environment $(2,21,22)$. Research by Shalley, for example, revealed significant relationships between authentic leadership and job satisfaction, positive working relationships, and trust in leadership (23). Workers who identified their leaders as authentic also were noted to have a high rate of job satisfaction, as well as positive relationships with leadership and coworkers. There is also a significant relationship between authentic leadership and loyalty and motivation of workers. Additionally, research on the impact of authentic leadership in nursing revealed that authentic leadership in nursing can improve patient safety and patient-care practices (24). Patient safety was improved because nurses had increased motivation, job satisfaction, and support, which led to better attention to patients and fewer patient-involved accidents. Patient-care practices were improved as indicated by a significant in- crease in patient satisfaction levels on surveys along with a decrease in reported safety incidents.

\section{AUTHENTIC LEADERSHIP DEVELOPMENT}

Authentic leadership development can begin with current leaders assisting followers in personal growth and in developing their own authenticity (6). When leaders lead with authenticity, they naturally serve as role models to their followers and support the development of authentic leadership traits. Managers and others in leadership positions may help develop a follower's self-awareness through life stories, which support personal and professional development. Further, nuclear medicine technology education can include some focus on self-awareness and authenticity to serve as a foundation for effective leadership. Preparing students with competencies in authentic leadership traits enables them to be effective health-care professionals and lays a solid foundation for future leadership. The addition of authentic leadership development to education may promote future graduates' continued involvement and advancement in the profession, though this type of support and encouragement for personal and professional development should be encouraged at any level of experience (6).

\section{CONCLUSION}

Authentic leadership theory combines leadership theory and humanism psychology theory to create a leadership style. Authentic leadership develops out of self-awareness, moral perspective, and balanced cognitive processing. An authentic leader has a respect for diversity and a concern for followers that yields positive results with respect to worker motivation, satisfaction, and completion of company goals. Being an authentic leader is not something one can declare for onself; rather, it is something one strives for and works hard at developing. Authentic leaders have a genuine desire to serve and empower others that supersedes the desire for power, money, or prestige. Passion for their purpose and compassion for others guide their leadership.

Authentic leadership theory offers a holistic perspective to true leadership. Encouragement and development of authentic leadership may have positive implications for patient care, staff retention, knowledge sharing, the work environment, and the future advancement of the nuclear medicine field. Particularly, nuclear medicine will need to develop a new generation of effective and authentic leaders who are able to face tough challenges to our field such as encroachment on the scope of practice, regulatory issues, and advocacy. The authentic leadership model continues to evolve; therefore, more research is needed to continue to develop and test the theory of authentic leadership, particularly regarding its practical applications and efficacy in nuclear medicine.

\section{DISCLOSURE}

No potential conflict of interest relevant to this article was reported. 


\section{REFERENCES}

1. George B. Authentic Leadership: Rediscovering the Secrets of Creating Lasting Value. San Francisco, CA: Jossey-Bass; 2003.

2. Alilyyani B, Wong C, Cummings G. Antecedents, mediators, and outcomes of authentic leadership in healthcare: a systemic review. Int J Nurs Stud. 2018;83: 34-64.

3. Authenticity. Cambridge Dictionary website. https://dictionary.cambridge.org/us/ dictionary/english/authenticity. Accessed April 25, 2019.

4. Covelli B, Mason I. Linking theory to practice: authentic leadership. Acad Strategic Manage J. 2017;16(3):1-10.

5. Gardner WL, Cogliser CC, Davis KM, Dickens MP. Authentic leadership: a review of the literature and research agenda. Leadership Q. 2011;22:1120-1145.

6. Avolio BJ, Gardner WL. Authentic leadership development: getting to the root of positive forms of leadership. Leadership Q. 2005;16:315-338.

7. Gardiner R. Authentic leadership through an ethical prism. Adv Hum Resources. 2017;19:467-477.

8. Murray T. Comparing Theories of Child Development. 6th ed. Boston, MA. Cengage Learning; 2005.

9. Maslow AH. A theory of human motivation. Psychol Rev. 1943;50:370-396.

10. Maslow AH. Toward a Psychology of Being. Princeton, NJ: D. Van Nostrand Company; 1962.

11. Maslow AH. Motivation and Personality. 3rd ed. Delhi, India: Pearson Education; 1987.

12. McLeod S. Maslow's hierarchy of needs. Simply Psychology website. www.simplypsychology.org/maslow.html. Updated 2018. Accessed April 25, 2019.
13. Heyler SG, Martin JA. Servant leadership: opportunities for additional theoretical integration. J Managerial Issues. 2018;30:230-240.

14. Minor JB. Organizational Behavior 1: Essential Theories of Motivation and Leadership. New York, NY: M.E. Sharpe; 2005.

15. Hinojosa AS, Davis McCauley K, Randolph-Seng B, Gardiner WL. Leader and follower attachment styles: implications for authentic leader-follower relationships. Leadership Q. 2014;25:595-610.

16. Shamir B, Eilam G. "What's your story?" A life-stories approach to authentic leadership development. Leadership Q. 2005;16:395-417.

17. Walumbwa FO, Avolio B, Gardner WL, Wernsing TS, Peterson SJ. Authentic leadership; development and validation of a theory-based measure. J Manage. 2008;34:89-126.

18. Neider LL, Schriescheim CA. The Authentic Leadership Inventory (ALI): development and empirical tests. Leadership Q. 2018;22:1146-1164.

19. Otaghsara SM, Hamzehzadeh H. The effect of authentic leadership and organizational atmosphere on positive organizational behavior. Int J Manage Accounting Econ. 2017;4:1122-1135.

20. Braun S, Peus C. Crossover of work-life balance perceptions: does authentic leadership matter? J Bus Ethics. 2018;149:875-893.

21. MacPhee M, Chang L, Lee D, Spiri W. Global health care leadership development trends to consider. J Healthcare Leadership. 2013;5:21-29.

22. Porter-O'Grady T. Leadership at all levels. Nurs Manage. 2011;42:32-37.

23. Shalley CE. Writing good theory: issues to consider. Organ Psychol Rev. 2012; 2:258-264.

24. Wong CA, Giallonardo LM. Authentic leadership and nurse-assessed adverse patient outcomes. J Nurs Manage. 2013;21:740-752. 